\title{
A AÇÃO CIVIL PÚBLICA DA LEI No 7.913/89 COMO AÇÃO COLETIVA DE CONSUMO: UM MECANISMO PARA A EFETIVIDADE DA JUSTIÇA CONTRATUAL NO BRASIL
}

Luiz César Martins Loques ${ }^{1}$

Milena Zampieri Sellmann ${ }^{2}$

Fabiano Moraes de Oliveira ${ }^{3}$

\section{Resumo:}

A tutela coletiva do acionista minoritário tem se tornado um desafio para os tribunais brasileiros e para a doutrina. Com o cenário fático cada vez mais complexo e dinâmico, diversas questões relativas à vulnerabilidade e à hipossuficiência tem ganho destaque nas discussões sobre disposições internas das companhias. Quando se aborda o tema sob o viés da Lei $\mathrm{n}^{\mathbf{0}} 7.913 / 89$, o debate se torna ainda mais amplo, justamente pela natureza da referida ação coletiva, quando de seu regime geral, admitir sua participação em relações de consumo. O objetivo é, sem dúvida, minorar as disparidades e buscar a justiça contratual.

Palavras-chave: Tutela Coletiva; Acionista Minoritário; Justiça Contratual; Mercado de Capitais; Consumidor

\section{PUBLIC CIVIL ACTION OF LAW NO. 7,913 / 89 AS COLLECTIVE ACTION FOR CONSUMPTION: A MECHANISM FOR THE EFFECTIVENESS OF CONTRACTUAL JUSTICE IN BRAZIL}

\begin{abstract}
:
The collective guardianship of the minority shareholder has become a challenge for Brazilian courts and for doctrine. With the factual scenario increasingly complex and dynamic, several issues related to vulnerability and hyposufficiency have gained prominence in the discussions on internal provisions of companies. When the subject is approached from the point of view of Law No. 7,913 / 89, the debate becomes even broader, precisely because of the nature of the referred collective action, when of its general regime, to admit its participation in consumer relations. The objective is undoubtedly to reduce disparities and seek contractual justice.
\end{abstract}

Keywords: Collective Guardianship; Minority Shareholder; Contractual Justice; Capital Market; Consumer.

\section{INTRODUÇÃO}

\footnotetext{
${ }^{1}$ Mestrando em Direito pelo UNISAL/SP. Especialista em Direito Empresarial e Notarial e Registral pela FUNIP/MG. Bacharel em Direito pelo UNIFOA/RJ. Advogado. Cointato: 1cloques@ gmail.com

${ }^{2}$ Especialista, Mestre e Doutora em Direito Tributário pelo PUC-SP. Professora da Graduação e Pós-Graduação em Direito do UNISAL. Professora do Damásio Educacional. Tabeliã e Oficiala em Minas Gerais. Contato: milenasellmann@hotmail.com

${ }^{3}$ Mestrando em Direito (Direitos sociais, econômicos e culturais) pelo UNISAL. Especialista em Direito pela UCAM. Graduado em Direito pela UFF e Ciências Contábeis pela UERJ. Auditor Fiscal Estadual. Contato: moraesfabiano@hotmail.com
} 
O direito societário brasileiro tem se mostrado cada vez mais complexo no que tange à natureza jurídica de suas relações. O debate fica ainda mais complexo quando levado ao microssistema coletivo das ações coletivas.

Como um desses instrumentos pouco utilizados, a Lei $\mathrm{n}^{\circ} 7.913 / 89$, ainda carece de maiores complementações e de uma abordagem mais firme da doutrina nacional, sobretudo da doutrina comercialista.

Em razão de sua natureza ainda pouco explorada, a exceção da definição legal desta ação coletiva, como ação civil pública, talvez seja oportuna dividi-la em dois âmbitos de aplicação desta ação, assim como existe no microssistema das ações coletivas com a ação civil pública chamada de "geral” regulamentada pela Lei nº7.347/85. É observável a aplicação da referida lei inclusive em relações consumeristas, onde são chamadas de ações coletivas de consumo.

No primeiro capítulo discutir-se-á a natureza jurídica da relação dos acionistas minoritários com a sociedade anônima em questão. Além disso, investigar-se-á a jurisprudência dos tribunais brasileiros, predominantemente do STJ, acerca da aceitação ou não de se configurar a relação societária em uma relação de consumo e o caminho que a doutrina mostra para o tema.

No segundo capítulo a discussão passa a um recorte da ação civil pública especial (da Lei $n^{\circ}$ 7.913/89) como uma ação coletiva de consumo e como os institutos típicos do CDC, em sua modalidade processual, auxiliam nessa perspectiva que alinhada à doutrina consumeristas, pode sugerir um maior grau de efetividade e paridade entre os contratantes da sociedade anônima em questão (vulneráveis ou não).

No terceiro capítulo a abordagem é ligada diretamente à efetividade da justiça. A tentativa será de demonstrar que o reconhecimento de um critério de vulnerabilidade do acionista minoritário em conjunto com um regime jurídico adequado à sua realidade - na hipótese a guia do CDC - importará no atingimento da justiça contratual, evitando comportamentos disformes e abusivos no direito societário.

O presente artigo preserva pertinência temática como o GT: "Processo, Jurisdição e Efetividade da Justiça", uma vez que trata exatamente do tópico: "Instrumentos e ferramentas processuais com vistas à efetividade da justiça".

Ao propor uma solução prática para a composição e tutela do acionista minoritário equiparando-o ao consumidor, na tutela coletiva nacional, amplia-se fortemente os poderes 
dos órgãos públicos, dos legitimados extraordinários e favorece os minoritários lesados, de modo a trazer a concepção ideal de "justiça contratual" ao processo coletivo brasileiro, no que se refere, especificamente, a tutela reparatória e inibitória societária.

\section{1 - DO ACIONISTA MINORITÁRIO COMO CONSUMIDOR}

As relações de consumo no direito privado moderno suscitam debates mais profundos do que a literalidade do CDC. Apesar de uma perspectiva de certa forma limitada nos conceitos de fornecedor e consumidor:

Art. $2^{\circ}$ Consumidor é toda pessoa física ou jurídica que adquire ou utiliza produto ou serviço como destinatário final.

Parágrafo único. Equipara-se a consumidor a coletividade de pessoas, ainda que indetermináveis, que haja intervindo nas relações de consumo.

Art. $3^{\circ}$ Fornecedor é toda pessoa física ou jurídica, pública ou privada, nacional ou estrangeira, bem como os entes despersonalizados, que desenvolvem atividade de produção, montagem, criação, construção, transformação, importação, exportação, distribuição ou comercialização de produtos ou prestação de serviços.

$\S 1^{\circ}$ Produto é qualquer bem, móvel ou imóvel, material ou imaterial.

$\S 2^{\circ}$ Serviço é qualquer atividade fornecida no mercado de consumo, mediante remuneração, inclusive as de natureza bancária, financeira, de crédito e securitária, salvo as decorrentes das relações de caráter trabalhista

o direito brasileiro atual moldou-se com base em duas teorias principais sedimentadas

na jurisprudência do STJ: a teoria maximalista e a teoria finalista aprofundada.

A primeira tem índole essencialmente ampliativa, fazendo uma interpretação literal do

art.29 do CDC. Sobre os pressupostos dessa teoria, destaca Fatima Nancy Andrighi (2004, p.6/8):

a) o conceito de consumidor direto, adotado pelo art. $2^{\circ}$ do CDC, é de índole objetiva, porquanto define o consumidor, tão-somente, em atenção à destinação dada à fruição do bem ou serviço adquirido ou utilizado, a qual deve ser final, isto é, capaz de consumi-lo ou utilizá-lo de forma a depreciar, invariavelmente, o seu valor como meio de troca; b) a demonstração de que o bem ou serviço foi adquirido ou utilizado para a destinação final, ainda que meramente fática, preenche o requisito necessário à definição de consumidor; c) a finalidade a ser satisfeita pelo ato de consumo não interfere na definição de relação de consumo, isto é, verificada a aquisição ou utilização para a destinação final, pouco importa se a necessidade a ser suprida com o consumo será de natureza pessoal ou profissional.; d) o uso profissional do bem ou serviço adquirido ou utilizado pela pessoa jurídica que exerce atividade econômica apenas afastará a existência de relação de consumo se tal bem ou serviço compor, diretamente (revenda) ou por transformação, beneficiamento ou montagem, o produto ou serviço a ser fornecido a terceiros, porquanto, em tais hipóteses, a destinação não será final, mas apenas intermediária.; e) a pessoa jurídica que exerce atividade econômica será consumidora sempre que o bem ou serviço for adquirido ou utilizado para destinação final; desnecessária, na hipótese, a demonstração de ser, a pessoa jurídica, parte vulnerável ou hipossuficiente (fático ou econômico, técnico ou jurídico) perante o fornecedor.

Algumas conclusões podem ser retiradas da citação acima. A primeira é o padrão de

que é desnecessária a prova de que o consumidor é o destinatário fático do bem, restando 
apenas a discussão acerca da destinação econômica deste. A única hipótese em que não haveria a aplicação da lei consumerista seria no uso profissional do bem, ocorrendo seu repasse ao destinatário final econômico do mesmo. Aqui, portanto, estar-se-ia diante de uma relação típica de intermediário para o profissional.

A jurisprudência do Superior Tribunal de Justiça, por voto da própria ministra Nancy Andrghi, já estabeleceu o critério da teoria maximalista para flexibilizar a lógica própria do CDC:

A relação jurídica qualificada por ser de 'consumo' não se caracteriza pela presença de pessoa física ou pessoa jurídica em seus pólos, mas pela presença de uma parte vulnerável de um lado (consumidor), e de um fornecedor, de outro. Mesmo nas relações entre pessoas jurídicas, se da análise da hipótese concreta decorre inegável vulnerabilidade entre pessoa-jurídica consumidora e a fornecedora, deve-se aplicar o CDC na busca do equilíbrio entre as partes. Ao consagrar o critério finalista para interpretação do conceito de consumidor, a jurisprudência do STJ também reconhece a necessidade de, em situações específicas, abrandar o rigor do critério subjetivo do conceito de consumidor, para admitir a aplicabilidade do CDC nas relações entre fornecedores e consumidores-empresários em que fique evidenciada a relação de consumo. São equiparáveis a consumidor todas as pessoas, determináveis ou não, expostas às práticas comerciais abusivas (...) Recurso especial não conhecido" (STJ - $3^{\mathrm{a} T}$. - REsp 476428/SC - rel. Min. Nancy Andrighi - j. 19.04.2005) (2005, s/p apud MARQUES; BEIJAMIN; MIRAGEM, 2013, p.56/57, grifo nosso).

Diante disso, será consumidor por equiparação todo aquele contratante que for exposto às práticas comerciais abusivas, independentemente do juízo de valor fático-jurídico acerca da hipossuficiência da mesma, já que a vulnerabilidade é sempre presumida nas relações de consumo.

Por outro lado, a teoria finalista aprofundada parte de outra premissa, levando à questão da vulnerabilidade como requisito essencial na formação da relação de consumo. Sobre seu surgimento, aduz Cláudia Lima Marques (2010, p.87 apud TARTUCE; NEVES, 2020, s/p):

Desde a entrada em vigor do CC/2002, parece-me crescer uma tendência nova da jurisprudência, concentrada na noção de consumidor final imediato (Endverbraucher), e de vulnerabilidade (art. $4^{\circ}, \mathrm{I}$ ), que poderíamos denominar aqui de finalismo aprofundado. É uma interpretação finalista mais aprofundada e madura, que deve ser saudada. Em casos difíceis envolvendo pequenas empresas que utilizam insumos para a sua produção, mas não em sua área de expertise ou com uma utilização mista, principalmente na área de serviços, provada a vulnerabilidade, conclui-se pela destinação final de consumo prevalente. Essa nova linha, em especial do STJ, tem utilizado, sob o critério finalista e subjetivo, expressamente a equiparação do art. 29 do CDC, em se tratando de pessoa jurídica que comprove ser vulnerável e atue fora do âmbito de sua especialidade, como hotel que compra gás. Isso porque o $\mathrm{CDC}$ conhece outras definições de consumidor. $\mathrm{O}$ conceito-chave aqui é o de vulnerabilidade.

. Em feliz exemplo, explica Rizzatto Nunes (2018, s/p): 
No que concerne à primeira relação jurídica (montadora e concessionária), nada muda, mantendo-se a relação civil, regida substancialmente pelo Código Civil de 2002. Porém, a relação estabelecida entre a empresa especializada em entregas e a concessionária não é uma relação de consumo pela teoria finalista. Isso porque tal empresa até pode ser destinatária final fática dos veículos, mas não é destinatária final econômica, por utilizar tais bens em sua atividade econômica predominante. Por fim, a empresa especializada em entregas rápidas será substituída por um taxista ou um caminhoneiro, que adquire o veículo para sua manutenção profissional. Mantendo-se mais uma vez a conclusão de que a primeira relação é civil, surge dúvida atroz a respeito da segunda relação, diante da patente disparidade que atinge o taxista e o caminhoneiro. Lembre-se de que, pela teoria finalista, ambos não seriam consumidores, já que retiram do veículo adquirido a sua atividade lucrativa primordial. Não haveria, portanto, a destinação econômica exigida para a caracterização do consumidor. Em casos como esse é que a doutrina e a jurisprudência têm reconhecido a aplicação da teoria maximalista mitigada ou da teoria finalista aprofundada.

A teoria supracitada parece solucionar problema que os maximalistas não conseguiram tornar suficientemente claro: qual é o critério identificador da parte para que seja caracterizada a relação de consumo?

Aos olhos do finalismo aprofundado é pacífica a ideia de que, na realidade, o que reservará a posição de consumidor ao contratante mais fraco é sua situação de disparidade com o contratante hipersuficiente ou não vulnerável. Dai a provocação do supracitado autor em substituir uma empresa de entregas por um taxista ou caminhoneiro. Não se poderia imaginar que pela complexa atuação de uma sociedade empresária de médio ou grande porte, sua relação a nível de realização de contrato seja o mesmo de uma pequena sociedade familiar que administra dois ônibus de turismo. A relação de consumo para os finalistas aprofundados está, portanto, na qualidade da parte e não nos termos do negócio jurídico em si, traduzindo, assim, um alto grau de subjetivismo à relação.

O Superior Tribunal de Justiça possui acórdão paradigmático sobre o tema:

A determinação da qualidade de consumidor deve, em regra, ser feita mediante aplicação da teoria finalista, que, numa exegese restritiva do art. $2^{\circ}$ do CDC, considera destinatário final tão somente o destinatário fático e econômico do bem ou serviço, seja ele pessoa física ou jurídica. Dessa forma, fica excluído da proteção do CDC o consumo intermediário, assim entendido como aquele cujo produto retorna para as cadeias de produção e distribuição, compondo o custo (e, portanto, o preço final) de um novo bem ou serviço. Vale dizer, só pode ser considerado consumidor, para fins de tutela pelo CDC, aquele que exaure a função econômica do bem ou serviço, excluindo-o de forma definitiva do mercado de consumo. Todavia, a jurisprudência do STJ, tomando por base o conceito de consumidor por equiparação previsto no art. 29 do CDC, tem evoluído para uma aplicação temperada da teoria finalista frente às pessoas jurídicas, num processo que a doutrina vem denominando 'finalismo aprofundado'. Assim, tem se admitido que, em determinadas hipóteses, a pessoa jurídica adquirente de um produto ou serviço possa ser equiparada à condição de consumidora, por apresentar frente ao fornecedor alguma vulnerabilidade, que constitui o princípio-motor da política nacional das relações de consumo, premissa expressamente fixada no art. $4^{\circ}, \mathrm{I}$, do CDC, que legitima toda a proteção conferida ao consumidor. A doutrina tradicionalmente aponta a existência de três modalidades 
de vulnerabilidade: técnica (ausência de conhecimento específico acerca do produto ou serviço objeto de consumo), jurídica (falta de conhecimento jurídico, contábil ou econômico e de seus reflexos na relação de consumo) e fática (situações em que a insuficiência econômica, física ou até mesmo psicológica do consumidor o coloca em pé de desigualdade frente ao fornecedor). Mais recentemente, tem se incluído também a vulnerabilidade informacional (dados insuficientes sobre o produto ou serviço capazes de influenciar no processo decisório de compra). Além disso, a casuística poderá apresentar novas formas de vulnerabilidade aptas a atrair a incidência do CDC à relação de consumo. Numa relação interempresarial, para além das hipóteses de vulnerabilidade já consagradas pela doutrina e pela jurisprudência, a relação de dependência de uma das partes frente à outra pode, conforme o caso, caracterizar uma vulnerabilidade legitimadora da aplicação do CDC, mitigando os rigores da teoria finalista e autorizando a equiparação da pessoa jurídica compradora à condição de consumidora" (STJ - REsp 1.195.642/RJ - Rel.Min. Nancy Andrighi - j. 13.11.2012) (apud TARTUCE; NEVES, 2020, s/p).

$\mathrm{O}$ finalismo aprofundado faz jus à conclusão de que o critério subjetivo ligado às partes é o preponderante, o que contribuiu com a ideia de que o principal elemento identificador da incidência do CDC seria a vulnerabilidade e hipossuficiência de uma das partes. Contudo, não parece que algumas características da doutrina maximalista devam se perder no cenário doutrinário e jurisprudencial, principalmente no que tange a premissa de exposição do consumidor às cláusulas abusivas - critério objetivo. Ainda que haja resistência doutrinária e uma tentativa da jurisprudência de entender que a teoria finalista aprofundada é uma evolução da própria teoria maximalista, em certo ponto, estas parecem complementares, de modo que não seria impossível a reprodução adaptada do acórdão acima citado:

São equiparáveis a consumidor todas as pessoas físicas e jurídicas, vulneráveis e hipossuficientes, que sejam expostas às relações jurídicas contratuais assimétricas. Em se observando práticas abusivas ou ilícitas, será aplicável, como diploma regente de solução do conflito, as normas protetivas do CDC, sem prejuízo da aplicação de outras normas que beneficiarem o contratante mais fraco (LOQUES, 2021, s/p).

Somando-se às duas concepções é possível chegar ao maior nível protetivo possível ao consumidor contratante. De um lado, observa-se que o destinatário econômico do bem - ainda que intermediário - será considerado consumidor caso preserve severa disparidade entre este e o fornecedor. Caso não contribua para essa visão, mas esteja exposto às cláusulas comerciais abusivas, será considerado consumidor por equiparação, nos termos do art. 29 do CDC.

Além dos critérios subjetivos e objetivos, é relevante também destacar a função que o próprio CDC cumpria antes da entrada em vigência do CC/02.

Após a edição da $\mathrm{CRFB} / 88$, o $\mathrm{CDC}$ era a única lei do direito privado nacional que possuía um sentido em harmonia com a lei maior. Extremamente vinculada aos princípios constitucionais e seus desdobramentos, a lei consumerista foi a primeira a trabalhar com a noção de boa-fé objetiva aliada as concepções de função social do contrato, valores esses 
extremamente ligados ao sentido mitigante do patrimonialismo exacerbado que foi um dos objetivos que o texto constitucional quis reservar ao direito privado.

Justamente por isso, até a edição do código Reale, muitas das relações interempresariais eram regulados pelo novel instituto, o que acarretou uma quebra de entendimento do sistema jurídico e, para que não houvesse conflito com a formação própria dos contratos mercantis e seus princípios específicos, tentou-se excluir completamente do raio de incidência do CDC o destinatário não final do produto, que em geral se transmuta de sociedade empresária. Sobre o fenômeno descrito:

[...] CC/2002 deve ter efeito útil (effetutile); logo, deve ter algum campo de aplicação privilegiado, e este é o dos contratos interempresariais, que não mais necessitam ser regulados pelo CDC (seja pela interpretação maximalista do art. $2 .^{\circ}$ do CDC, seja pela expansão protetiva do art. 29 do CDC a todos os contratos de adesão). Os contratos interempresariais não mais necessitam ser regulados pelo CDC, pois o CC/2002 traz os mesmos princípios protetores (boa-fé objetiva, onerosidade excessiva, lesão etc.) e ainda normas específicas para regular as relações entre iguais. Assim, em caso envolvendo uma incorporadora e um banco de crédito imobiliário, o STJ aplicou o Código Civil de 2002 e o princípio da função social do contrato de crédito imobiliário, de forma imediata, com base no polêmico art. 2.035 do CC/2002, para fracionar a hipoteca, em última análise, a favor dos consumidores! (MARQUES; BEIJAMIN; MIRAGEM, 2013, p.57, grifo nosso).

Evidentemente, quando for possível utilizar-se de regras mais protetivas entre uma lei e outra, privilegiar-se-á a que melhor desempenhar esse papel, em virtude da observação ao diálogo das fontes entre CC/02 e CDC.

Adicionando-se a esse debate, a doutrina não é reticente em afirmar que apesar da evolução da teoria finalista aprofundada e da regulamentação do código civil atual, apenas o CDC seria o verdadeiro dispositivo apto a regulamentar as relações, no direito privado, entre partes desiguais, desde que fosse reconhecido como elemento que denotasse a disparidade. Os maximalistas dão como exemplo a própria existência do contrato de adesão nas relações típicas de consumo:

Concluímos, então, dizendo que o Código de Defesa do Consumidor é totalmente aplicável aos contratos de adesão, em virtude da extensão do conceito de consumidor, equiparando a este todas as pessoas expostas às práticas previstas nos seus Capítulos V e VI, estando, como é sabido nos contratos de adesão disciplinados dentro desse último. E isso ocorre porque a intenção do legislador, ao elaborar o Código de Defesa do Consumidor, foi garantir justiça e equidade aos contratos realizados sob sua égide, para equilibrar partes contratuais em posições diferentes, tutelando de modo especial o partícipe contratual, que julgou ser vulnerável. Assim, entendeu o legislador que a simples exposição às práticas por ele previstas no CDC era suficiente para gerar uma situação de insegurança e de vulnerabilidade, considerando, portanto, que o simples fato de se submeter a um contrato de adesão colocava o aderente em posição inferior, se equiparando ao consumidor (NOVAES, 2001, p.165). 
Se ampliarmos esse raciocínio, o CC/02 passa então a ser o diploma regente de negócios jurídicos firmados entre partes iguais, o que sugeriria o protagonismo de boa parte das relações empresariais (MARQUES; MIRAGEM, 2012), ainda que não se esteja falando exclusivamente da perspectiva contratualista clássica.

Existem relações empresariais que não comportam, por sua própria natureza, a obrigatoriedade de paridade econômica, jurídica e informacional entre as partes. Prova maior disso está nas sociedades empresárias de grande porte, onde os componentes desta, se individualmente considerados, jamais se tornarão tão hipersuficientes quanto à própria sociedade.

No seio das sociedades anônimas, os acionistas minoritários com ínfimo percentual do capital social da companhia parecem representar bem essa relação.

Os acionistas minoritários quando representados em um bloco, em certa medida, representam algum poder decisório no âmbito interno da relação societária, formando um direito de minoria, como acontece na hipótese prevista no art.161, $\S 2^{\circ}$ da LSA:

Art. 161. A companhia terá um conselho fiscal e o estatuto disporá sobre seu
funcionamento, de modo permanente ou nos exercícios sociais em que for instalado
a pedido de acionistas.
$\S 1^{\circ} \mathrm{O}$ conselho fiscal será composto de, no mínimo, 3 (três) e, no máximo, 5 (cinco)
membros, e suplentes em igual número, acionistas ou não, eleitos pela assembléia-
geral.
$\S 2^{\circ} \mathrm{O}$ conselho fiscal, quando o funcionamento não for permanente, será instalado
pela assembléia-geral a pedido de acionistas que representem, no mínimo, 0,1 (um
décimo) das ações com direito a voto, ou $5 \%$ (cinco por cento) das ações sem direito
a voto, e cada período de seu funcionamento terminará na primeira assembléia-geral
ordinária após a sua instalação.

$\mathrm{Na}$ hipótese acima, resta claro que até mesmo uma pequena parte dos acionistas ordinários da companhia - é legitimada a instalar, enquanto órgão não permanente, o conselho fiscal. Logo, deve-se destacar que os minoritários não são meros expectadores da gestão da sociedade anônima, de modo que sempre estejam ali apenas aportar capital na companhia e esperar o pagamento dos resultados inerentes ao exercício social.

Até mesmo no caráter individual, o acionista minoritário possui relevância na companhia, já que o art.123, parágrafo único, alínea ' $b$ ' da LSA prevê a legitimidade especial de qualquer acionista - aqui incluído o minoritário - para fazer a convocação da assembleia geral de acionistas, quando ordinária, caso o administrador a retarde por mais de 60 dias. Modesto Carvalhosa (2011, p.814) traz à luz o dispositivo:

Em se tratando de assembleia ordinária, há uma preferência de ordem para o Conselho Fiscal que poderá convocá-la, se os administradores retardarem a medida por mais de trinta dias. Somente após decorridos sessenta dias do prazo legal (art. 
132) e não tendo, por sua vez, o Conselho Fiscal ou qualquer de seus membros cumprido essa obrigação, caberá aos acionistas promoverem a convocação ut singuli. Essa faculdade cabe a qualquer acionista, independentemente de percentual que possua no capital social e de suas ações lhe atribuírem ou não direito de voto.

Demonstrada a relevância dos minoritários no quadro societário da companhia, devese arguir se seu regime de direitos é proporcional ao tratamento que o ordenamento jurídico reserva aos mesmos.

Parece claro que há uma desproporção de forças e de poderes entre os acionistas minoritários e os próprios órgãos da companhia e os demais acionistas. Não obstante, as manifestações do poder judiciário são, quase sempre, na tentativa de relativizar esses entendimentos de fragilidade contratual do minoritário. Segundo o entendimento do Superior Tribunal de Justiça (2020, s/p):

No voto seguido pela maioria do colegiado, o ministro Villas Bôas Cueva destacou que o STJ se orienta pela teoria finalista ou subjetiva, segundo a qual o conceito de consumidor, para efeito de incidência das normas protetivas do CDC, leva em conta a condição de destinatário final do produto ou serviço, nos termos do artigo $\mathbf{2}^{\circ}$ do código.

"Segundo a teoria subjetiva ou finalista, destinatário final é aquele que última a atividade econômica, isto é, que retira de circulação do mercado o bem ou o serviço para consumi-lo, suprindo uma necessidade ou satisfação própria", explicou o ministro, ao também ressaltar as diferenças entre relação de consumo (consumidor final) e relação de insumo (consumidor intermediário).

Para o ministro, o investidor, ao adquirir ações no mercado imobiliário visando o recebimento de lucros e dividendos, não está abrangido pela proteção do CDC.

A proposta dos ministros que seguiram esse entendimento foi coerente com a jurisprudência mais recente da corte, ainda que seja possível questioná-la dentro de seu aspecto interno ${ }^{4}$. Continua o ministro relator Villas Bôas Cueva: "A não adequação aos conceitos legais de consumidor e fornecedor descaracteriza a relação jurídica de consumo, afastando-a, portanto, do âmbito de aplicação do Código de Defesa do Consumidor" (STJ, 2020, p.35).

Ainda apegada ao extremo subjetivismo da relação consumerista, a jurisprudência nacional, sobretudo nos tribunais superiores, ignora a face objetiva da relação de consumo presente na dicção do art.29 do CDC. Ao abordá-la, é coerente imaginar que os acionistas

\footnotetext{
${ }^{4}$ A impropriedade do entendimento do relator se encontra na constatação de que o acionista não é o destinatário final do bem. Ainda que o acionista possa auferir vantagens econômicas em decorrência da fruição do valor mobiliário, ele não está passando a frente o mesmo, fazendo seguir a cadeia de consumo. Ao contrário, sua posição não é de intermediário, mas sim de consumidor final, já que é a última pessoa a manter qualquer relação de direito real com o bem. Em simples analogia, alguém diria que o comprador "pessoa física" que adquire um imóvel de uma incorporada, frui deste por um tempo e ao mudar-se, coloca o apartamento para locação, não é consumidor? A resposta aparentemente é negativa. Em uma ação de vício construtivo, por exemplo, parece claro que a demanda judicial correrá pela base de direito material da relação de consumo, em observância estrita a qualidade subjetiva do comprador como "consumidor", uma vez que este é o proprietário do bem.
} 
minoritários estão expostos a práticas abusivas de outros membros da companhia quase que diariamente, uma vez que não são poucas as possibilidades de intercorrências desta natureza. E quando de fato se materializarem esses abusos, será aplicado ao minoritário o mesmo regime jurídico estático de outros acionistas com maior poderio econômico?

A resposta mais coerente parece aponta que não. $\mathrm{O}$ discurso de proteção do mercado e da intangibilidade das relações societárias pode ser prática aos contratantes mais fortes, mas péssima aos mais vulneráveis. Prova disso se encontra na inadmissão da aplicação do art.4 $4^{\circ}$, $\S 2^{\circ}$ da Lei $n^{\circ} 9.307 / 96$ (norma protetiva do consumidor) em conjunto com a cláusula arbitral estatutária prevista no art.109, $\S 3^{\circ}$ da LSA. Nas palavras de Walfrido Warde Jr. e Fernando Antônio Maia da Cunha (2012, p.749/750 apud FRANZONI, 2015, p.70):

Não é o caso. Nem mesmo o da grande companhia aberta, cujas ações são negociadas milhares de vezes ao dia em mercados bolsistas. Quem o faz, mesmo que queira ignorar as peculiaridades do mercado acionário, participa de negócios em um contexto de alta sofisticação; não o faz para satisfazer necessidades essenciais e, exatamente porque a poupança é pressuposto do negócio, não é hipossuficiente em sentido econômico. As eventuais assimetrias de informação não são capazes de caracterizar uma hipossuficiência informacional, uma vez que no mercado acionário - em vista de suas características regulatórias - a informação flui em maior abundância e qualidade do que em outros mercados

Aqui, o minoritário que, porventura, seja hipossuficiente econômico terá que se submeter ao caro procedimento arbitral, sendo lhe vedado o acesso à jurisdição estatal pela cláusula exposta, o que denota uma violação ao princípio da inafastabilidade da jurisdição e do acesso à justiça.

A doutrina, contudo, é fiel ao mesmo caminho de inaplicabilidade do CDC nas relações entre acionista e sociedade pela posição subjetivista. Posiciona-se José Geraldo de Brito Filomeno (1991, p.37):

E os investidores no mercado de valores mobiliários, serão eles considerados também consumidores com relação às instituições ou empresas que propiciam tal tipo de investimento? $\mathrm{E}$ a resposta é certamente negativa. $\mathrm{E}$, tanto isso é verdade que a recente Lei $\mathrm{n}^{\mathbf{0}}$ 7.913, de 7-12-89, previu ações específicas de ressarcimento a investidores, prevendo ainda a Lei $\mathrm{n}^{\circ}$ 6.024, de 13-03-1974, medidas acautelatórias quando se tratar de liquidação extrajudicial de instituições de crédito

Ao aplicar o conceito misto proposto anteriormente, onde claramente a visão objetiva da relação de consumo induziria à aplicabilidade da Lei no 8.078/90, é perceptível o regime de vulnerabilidade contratual entre as partes, uma vez que o estatuto da companhia é uma modalidade de contrato plurilateral (ASCARELLI, 2001).

Ao levar a discussão para o campo da tutela coletiva, discorda-se do anteriormente referido mestre das arcadas, para se conceber que a ação civil pública da Lei nº 7.913/89 pode 
ser considerada, sim, como uma ação coletiva de consumo e não como uma modalidade especial da ação civil pública pensada para a exclusão do CDC nesses tipos de contratos.

\section{2 - DA AÇÃo CIVIL PÚBLICA ESPECIAL COMO AÇÃO COLETIVA DE CONSUMO}

A lei 6.404/76, em seu bojo individual, fora do microssistema coletivo das ações coletivas concebe diversas modalidades de ações societárias, sendo estas dividas em três modalidades: ações anulatórias: ação anulatória de constituição da companhia e ação anulatória de deliberação assemblear; ações de reparação civil: 1) ação de reparatória de avaliação dos bens, ação reparatória por atos viciados com culpa ou dolo, ação de reparatória contra o agente fiduciário por atos viciados com culpa ou dolo, ação reparatória por violação do dever de sigilo, ação reparatória de credores não pagos na liquidação e ação reparatória para pagamento de dividendos disponíveis; ações de restituição: ação de restituição de dividendos recebidos de má-fé e ação de restituição de lucros recebidos de má-fé. Por fim, existem as ações genéricas: a ação geral do acionista e ação originada de fato que deva ser apurado em juízo criminal (BANDEIRA DE MELLO, 2017, p.323/325, grifo nosso).

Contudo, não são dessas ações que a Lei $n^{\circ}$ 7.913/89 faz referência, tampouco é uma modalidade subsidiária destas. Ou até mesmo, é uma ação que reproduze no âmbito coletivo, os ditames das ações individuais da LSA.

Dona de um regime jurídico próprio, que inclusive, a diferencia das outras ações coletivas, como acontece em seu procedimento de habilitação individual previsto em seu $\operatorname{art.} 2^{\circ}$.

O rol de atos previstos para coibição pela tutela coletiva do acionista minoritário é exemplificativo. Diante das diversas formas de manifestação de abusos que podem ocorrer no âmbito interno de uma sociedade anônima, cuja principal vítima é o acionista minoritário,

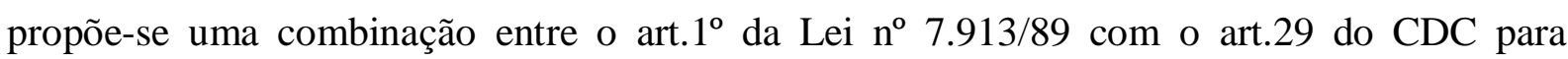
algumas situações

Como objeto da ação coletiva é a reparação dos investidores no mercado de capitais, poder-se-ia sugerir que duas etapas pudessem ser construídas para a transformação da natureza jurídica da ação coletiva da Lei $\mathrm{n}^{\circ}$ 7.913/89 em uma ação coletiva de consumo. A primeira estaria no critério subjetivo da teoria finalista aprofundada. Caso seja identificado que o acionista minoritário é, de fato, vulnerável na relação societária, incluídas aqui, as 
noções de vulnerabilidade socioeconômica, informacional e jurídica, será o acionista minoritário considerado consumidor, pela perspectiva subjetiva, ou seja, pela qualidade de parte como consumidor, nos exatos termos do que defendem os finalistas, na vertente aprofundada.

O segundo filtro seria o critério objetivo da relação consumerista. Constatada a exposição daquele acionista minoritário e vulnerável à exposição de uma prática contratual abusiva, será incidente a relação de consumo no caso concreto.

A utilização de mecanismos típicos das relações de consumo abarca essa relação, como acontecerá com a inversão do ônus da prova tão celebradas no CDC, como um elemento concretizador da paridade de armas no processo.

Além dela, também aparecerão como mecanismos aliados aos acionistas minoritários tidos por consumidores, as tutelas provisórias e a tutela inibitória que nas relações consumeristas são tão importantes, com destaque da tutela de urgência e da tutela inibitória.

Um bom exemplo para emendar os três mecanismos seria na hipótese de surgimento de uma demanda oriunda do art. $1^{\circ}$, III da Lei $n^{\circ} 7.913 / 89$. Em outras palavras, a utilização de forma fraudulenta ou simples omissão de informação pelo administrador da companhia é considerada um ilícito civil, apto a ser combatido em juízo pelos acionistas da companhia, caso o ato traduzisse prejuízo a estes.

Em situação hipotética em que o administrador da sociedade anônima " $x$ " omite informação relevante quanto ao balanço econômico-financeiro da companhia, o que faz com que os acionistas, ao se afetarem por uma falsa percepção da realidade, entendam que os negócios sociais traduzem resultados positivos, levando a assembleia geral de acionistas a aprovar o aumento do capital social da companhia, colocando novas ações no mercado de capitais.

Ao adquirirem as novas ações, uma nova série de minoritários surgirão, de modo que experimentarão apenas prejuízos ao ingressarem no quadro de sócios da companhia, perdendo todo o capital investido.

Ao analisar o catastrófico cenário exposto, o regime de responsabilidade poderá ser atribuído, majoritariamente ao administrador, que ao omitir prejuízo severo que a companhia sofrera em seu balanço, foi, no mínimo, imprudente. Comporá o litisconsórcio junto ao administrador, a sociedade, uma vez que dificilmente a pessoa natural responsável pela administração conseguirá, sem flertar com a insolvência civil, ressarcir os acionistas lesados. 
A primeira a se manifestar no caso concreto será a inversão do ônus da prova, caso a ação seja movida pelos acionistas minoritários que passem pelas características expostas anteriormente. Como a prova da omissão é muito complexa, envolvendo necessariamente questões contábeis para a análise do balanço, é mais condizente com a vulnerabilidade informacional de uma das partes, que o administrador e a companhia façam prova de que a omissão da informação não existiu, sendo a decisão de aumento do capital uma opção exclusiva e ambiciosa da assembleia geral de acionistas, por exemplo.

A segunda ferramenta que contaria em favor dos acionistas seria a incidência da tutela inibitória na ação coletiva em comento. Nesse sentido, como o único objetivo da tutela em questão é o combate amplo e irrestrito ao ato ilícito (LOPES; LOPES, 2017), o âmbito do CDC é mais favorável a essa percepção do que qualquer outra lei que pudesse dar base ao direito material no caso concreto.

Como avalia a própria lei consumerista, é ampla no texto desta as mais varias hipóteses de garantia do contratante a informação correta. Ora, apresentada como direito básico do consumidor (art. $6^{\circ}$, III do CDC), ora como prática comercial abusiva, nos termos do art.31 do CDC.

Logo, ainda que não houvesse surgido prejuízo aos minoritários vulneráveis, estes pelo rito do CDC, já teriam direito a demonstrar judicialmente o ilícito por omissão praticado pelo administrador, ainda que o prejuízo só a frente fosse demonstrado (ARBS, 2015).

Quanto a tutela cautelar, essa parece seguir o mesmo caminho. Ainda que parte da doutrina não tenha considerado o fim do processo cautelar autônomo (NEVES, 2016), unânime é que esta pode ser requerida de forma antecedente.

Nas relações de consumo a tutela cautelar antecedente ganha proporções maiores de importância diante do dever da legislação para com o consumidor, materializada no $\operatorname{art} .6^{\circ}$, VI do CDC, a saber: "a efetiva prevenção e reparação de danos patrimoniais e morais, individuais, coletivos e difusos" (BRASIL, 1990, s/p).

Diante disso, o caráter preventivo é sopesado pelo magistrado nas relações consumeristas. Caso o Ministério Público (entendimento tradicional - DINIZ, 2019) ou a associação de investidores representantes dos acionistas minoritários e quaisquer legitimados ativos do $\operatorname{art.5}^{\circ}$ da Lei $\mathrm{n}^{\mathrm{o}}$ 7.347/85 (LOQUES; SELLMANN, 2021 - entendimento minoritário) ingressassem com o pedido cautelar primeiro e sendo esse atendido pelo magistrado, este estará apto a formar coisa julgada material, desde que dele não decorra 
omissão quanto ao recurso de apelação que enfrentaria a sentença de concessão da tutela cautelar (CAHALI, 2018).

Adaptando ao caso hipotético mencionado, se o pedido de tutela cautelar de impedimento de repetição de informação danosa pelo administrador fosse deferido e não desafiasse recurso dos legitimados passivos ou contestação, estariam, evidentemente, limitados a não arguição desta matéria no bojo da ação principal, que viria a ser emendada no prazo de 30 dias previstos no Código de Processo Civil (BRASIL, 2015).

Por fim, o que se pode concluir neste capítulo é pela completa relevância de se conhecer a ação civil pública especial de tutela do acionista minoritário como uma ação coletiva de consumo, quando a situação de fato (critério objetivo) e a qualidade das partes (critério subjetivo) requer o procedimento específico da tutela coletiva e a face material do CDC, por ser a relação considerada de consumo no caso concreto.

\section{3 - DA EFETIVAÇÃo DA JUSTIÇA CONTRATUAL NAS RELAÇÕES SOCIETÁRIAS}

O principal objetivo da divisão proposta é efetivar a noção de justiça contratual nas relações societárias que demandam desproporção de poderio entre as partes, denotando a vulnerabilidade destas. Não é concebível que numa ordem jurídica justa, contratantes que compartilham dos mesmos resultados, ainda que de riscos diferentes, tenham um tratamento isonômico do ponto de vista formal e apenas isso.

A noção de justiça contratual não se limita apenas ao aspecto de proporcionalidade das prestações a que cada uma deve. Se assim fosse, não haveria qualquer problema advindo dos casos base deste trabalho, já que o acionista minoritário e os demais contribuem proporcionalmente ao capital social da sociedade anônima. A discussão abrange também o tratamento jurídico que é dado ao contratante, prestigiando um tratamento isonômico material às partes no litígio.

Se a situação fática não permite a materialização deste tratamento, sob pena de se violar os princípios próprios e inerentes do direito comercial, tal como ocorre com o princípio majoritário nas deliberações sociais, então o mesmo virá de um elemento externo à relação contratual, advindo, portanto, da lei e, quando provocado, ratificado pelo poder judiciário, quando da escolha do procedimento adotado e a lei que dá suporte à resolução do conflito. No caso específico, o CDC. 
Quando se avalia o comportamento da ação civil pública especial, tem-se firmado que não parece ser impensável considerá-la também como uma ação de consumo dentro da tutela coletiva, já que se está diante de um típico caso de direitos individuais homogêneos.

A justiça contratual, então, se materializará pela mesma condição que as partes terão, no processo, na mesma medida em que disporão de paridade de armas, para enfrentar a prática abusiva surgida dentro da companhia. A justiça contratual não se realiza apenas em sua formação e em seus desdobramentos no direito material, mas também com as faces processuais que são inerentes ao conflito.

\section{CONCLUSÃO}

Conclui-se, portanto, que a Lei $\mathrm{n}^{\mathrm{o}} 7.913 / 89$ pode ser interpretada perfeitamente de duas formas distintas. A primeira como uma ação instrumental de interesses dos investidores no mercado de capitais independentemente do critério de vulnerabilidade ou hipossuficiência do acionista, uma vez que a lei não faz distinção entre aspectos materiais dos legitimados ativos. Ao contrário, amplia o espectro de incidência da lei para abarcar qualquer acionista lesado, inclusive os mais economicamente poderosos, como o controlador.

A segunda, por sua vez, se comportaria com um instrumento protetivo daqueles acionistas que não terão outro instrumento a não ser a gratuidade majoritária da ação coletiva de consumo, aqui travestida de ação civil pública de proteção do investidor no mercado de capitais. Não há incompatibilidade na regra específica, se o tratamento processual da lei geral é pacífico. Não resta dúvidas de que a ação civil pública pode discutir questões que envolvam consumo, inclusive sejam direitos difusos, coletivos em sentido estrito ou individuais homogêneos.

Acompanhada da conclusão na face processual, igualmente pode-se firmar o entendimento de que o acionista minoritário, pelas condições que o CDC oferece, pode ser considerado consumidor, ainda que por equiparação, já que o tratamento dispensado a ele é, em última instância da relação contratual e não de qualidade da parte, ainda que essa visão não seja majoritária na jurisprudência nacional.

$\mathrm{O}$ CDC nasceu para tutelar as relações entre partes desiguais ou expostas às práticas comerciais abusivas nos exatos termos da teoria maximalista. Não se trata de uma disposição de partes no contrato, mas sim do próprio sentido de existência da lei. 
Assim, parece não restar outra opção para trazer a justiça contratual à tutela coletiva do acionista minoritário, conforme regulamentação da Lei no $7.913 / 89$, que não tratá-lo como consumidor e dispensá-lo todas as normas protetivas de origem material ou processual do CDC.

\section{REFERÊNCIAS}

ANDRIGHI, Fátima Nancy. O conceito de consumidor direito e a jurisprudência do Superior Tribunal de Justiça. Revista de Direito Renovar, Rio de Janeiro, n. 29, p. 1- 11, maio/ago. 2004. Disponível em: https://core.ac.uk/download/pdf/79058505.pdf. Acesso 25 mar.2020.

ARBS. Paula Saleh. A importância da ação inibitória na tutela de direitos. Dissertação de Mestrado na área de especialização em Ciências Jurídico-Civilísticas/menção em Direito Processual Civil, apresentada à Faculdade de Direito da Universidade de Coimbra. Disponível em: https://estudogeral.sib.uc.pt/handle/10316/30210. Acesso em 12 mar.2021.

ASCARELLI, Tullio. O contrato plurilateral. In: Problemas das sociedades anônimas e direito comparado. $1^{\text {a }}$ ed. Campinas/SP: Ed.Bookseller, 2001.

BANDEIRA DE MELLO, Leonardo Botelho. Lei das Sociedades Anônimas. Coleção leis especiais para concursos. $3^{\mathrm{a} e d . r e v ., ~ a t u a l . ~ e ~ a m p l . . ~-~ S a l v a d o r: ~ E d . ~ J u s p o d i v m, ~} 2017$.

BRASIL. Lei no 6.404/76. Dispõe sobre as sociedades por ações. Disponível em: http://www.planalto.gov.br/ccivil_03/leis/16404consol.htm. Acesso em: 19 mar. 2021.

Lei $n^{\circ} 7.913 / 89$. Dispõe sobre a ação civil pública de responsabilidade por danos causados aos investidores no mercado de valores mobiliários. Disponível em: http://www.planalto.gov.br/ccivil_03/leis/17913.htm. Acesso em: 2 out. 2020.

. Lei $\mathrm{n}^{\circ} 8.078 / 90$. Dispõe sobre a proteção do consumidor e dá outras

providências. Disponível em: http://www.planalto.gov.br/ccivil_03/leis/18078compilado.htm. Acesso em: 08 out.2020.

. Lei $\mathrm{n}^{\circ}$ 9.307/96. Dispõe sobre a arbitragem. Disponível em: http://www.planalto.gov.br/ccivil_03/leis/19307.htm\#: :text=LEI\%20N\%C2\%BA\%209.307\% 2C\%20DE\%2023,Disp\%C3\%B5e\%20sobre\%20a\%20arbitragem.\&amp;text=Art.,relativos\% 20a\% 20direitos\%20patrimoniais\%20dispon\%C3\%ADveis. Acesso em: 10 out.2020.

Lei 13.105/15. Código de Processo Civil. http://www.planalto.gov.br/ccivil_03/_Ato2015-2018/2015/Lei/L13105.htm. Acesso em 10 mar.2021.

CAHALI, Cláudia Elisabete Schwerz. Tutela cautelar antecedente. Enciclopédia jurídica da PUC-SP. Celso Fernandes Campilongo, Alvaro de Azevedo Gonzaga e André Luiz Freire (coords.). Tomo: Processo Civil. Cassio Scarpinella Bueno, Olavo de Oliveira Neto (coord. de 
tomo). 1. ed. São Paulo: Pontifícia Universidade Católica de São Paulo, 2017. Disponível em: https://enciclopediajuridica.pucsp.br/verbete/165/edicao-1/tutela-cautelar-antecedente

CARVAlHOSA, Modesto. Comentários à Lei de Sociedades Anônimas, v. 2. $5^{\text {a }}$.ed. São Paulo: Ed. Saraiva, 2011.

DINIZ, Gustavo Saad. Intervenção amicus curiae: sentido e alcance. In: ABRÃO, Carlos Henrique; CARVALHOSA, Modesto; LUCON, Paulo Henrique dos Santos. A tutela coletiva do acionista minoritário: Os 30 anos de vigência da Lei 7.913/89 - uma visão prospectiva construtiva. São Paulo: Quartier Latin, 2019.

FILOMENO, José Geraldo de Brito. Manual de direitos do consumidor. $2^{\mathrm{a}}$ ed. São Paulo: Ed. Atlas, 1991.

FRANZONI, Diego Ricardo Camargo. Arbitragem societária: fundamentos para uma possível regulação. 2015. Dissertação (Mestrado em Direito Comercial) - Faculdade de Direito, Universidade de São Paulo, São Paulo, 2015. doi:10.11606/D.2.2015.tde-06112015160316. Acesso em: 20 dez.2020.

LOPES, João Batista, LOPES, Maria Elizabeth de Castro. Tutela inibitória. Enciclopédia jurídica da PUC-SP. Celso Fernandes Campilongo, Alvaro de Azevedo Gonzaga e André Luiz Freire (coords.). Tomo: Processo Civil. Cassio Scarpinella Bueno, Olavo de Oliveira Neto (coord. de tomo). 1. ed. São Paulo: Pontifícia Universidade Católica de São Paulo, 2017. Disponível em: https://enciclopediajuridica.pucsp.br/verbete/164/edicao-1/tutela-inibitoria

LOQUES, Luiz César Martins; SELlMANN, Milena Zampieri. A Ação Civil Pública e a Proteção Jurídica dos Titulares de Valores Mobiliários: o Uso da Tutela Coletiva para a Coibição dos Atos do Insider Trading. REVISTA BRASILEIRA DE DIREITO COMERCIAL. Lex Magister. Edição nº 38. v. VII, p. 31-46, dez/jan.2021.

LOQUES, Luiz César Martins. A ação civil pública da lei no 7.913/89 como instrumento processual efetivo ao acionista hipossuficiente. No prelo.

MARQUES, Claudia Lima; MIRAGEM, Bruno. O novo direito privado e a proteção dos

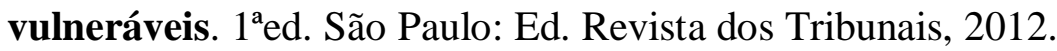

; BENJAMIN, Antônio Herman V.; MIRAGEM, Bruno. Comentários ao Código de Defesa do Consumidor. 4ªed. São Paulo: Ed. Revista dos Tribunais, 2013.

O processo cautelar autônomo não foi suprimido pelo novo CPC. In: Curso Forum. São Paulo, 2016. Disponível em: https://www.youtube.com/watch?v=q4AYV5AREDU\&list=FLDywMlapH1EaxMJmVnU70Q\&index=4. Acesso em 12 mar.2021.

NOVAIS, Alinne Arquette Leite. A teoria Contratual e o código de defesa do consumidor. $1^{\text {a}}$ ed. São Paulo: Ed. Revista dos Tribunais, 2001.

NUNES, Luiz Antônio Rizatto. Curso de Direito do Consumidor. 12ª . ed. São Paulo: 
SaraivaJur, 2018.

STJ. RECURSO ESPECIAL No 1.685.098/SP. Rel. Min. Moura Ribeiro p/acórdão Min. Ricardo Villas Bôas Cueva. $3^{\text {a }}$ Turma. Julgado em 10/03/2020. Site oficial do STJ.

Disponível em: https://www.conjur.com.br/dl/acordao-stj-acoes-recurso.pdf. Acesso em: 22 mar.2021.

Terceira Turma afasta relação de consumo entre acionistas minoritários e

sociedade de capital aberto. STJ notícias. 25 jun.2020. Disponível em:

https://www.stj.jus.br/sites/portalp/Paginas/Comunicacao/Noticias/Terceira-Turma-afastarelacao-de-consumo-entre-acionistas-minoritarios-e-sociedade-de-capital-aberto.aspx. Acesso em 28 mar.2021.

TARTUCE, Flávio; NEVES, Daniel Amorim Assumpção. Manual de Direito do Consumidor: direito material e processual. $9^{\mathrm{a}}$ ed. Rio de Janeiro; Forense; São Paulo; Método, 2020. 